\title{
L'ESTUDI DE LA PIRATERIA A TRAVÉS DELS AVISAMENTS COSTANERS. REPLEGAMENT CRISTIÀ I SETGE ISLÀMIC A LA VALÈNCIA DE LA TRANSICIÓ A LA MODERNITAT: $1480-1520$
}

\begin{abstract}
SUMARI
I. La defensa antipirata i el seu reflex documental: els albiraments d'enemics.II. Els avisaments costaners sobre els pirates musulmans: 1480-1520.- III. Els avisaments costaners sobre els pirates cristians: 1480-1520.- IV. Balanç final.
\end{abstract}

En pla sintètic, es podria afirmar que les fonts per a l'estudi de la pirateria poden ésser de tres tipus: privades, de l'administració reial i de l'administració municipal '. Sense restar importància a les dues primeres fonts documentals, les informacions que proporciona l'Arxiu Municipal de València, en referència al problema del cors, han de considerar-se com a excepcionals per llur diversitat $\mathrm{i}$ sobretot per llur continuïtat. El present treball se centra en una de les fonts locals essencials per a l'estudi de la pirateria a través de les notícies rebudes en el si del Consell de la capital valentina, durant el període 1480-1520, i per a l'àmbit geogràfic que, tot tenint com a prioritat les costeres valencianes, es refereix també a l'àrea dels Països Catalans de la Corona d'Aragó i per extensió a tota la façana peninsular mediterrània.

\section{LA DEFENSA ANTIPIRATA I EL SEU REFLEX DOCUMENTAL: ELS ALBIRAMENTS D'ENEMICS}

Entre les cartes que hem tingut l'oportunitat de revisar, en la secció de Lletres Missives de l'Arxiu Municipal de València, n'hem trobat algunes amb una tipologia ben definida, que poden qualificar-se com a avisos costaners ${ }^{2}$. Gràcies a aquestes,

1 Entre les fonts privades ressalten els contractes d'assegurances davant de possibles pèrdues de mercaderies $\mathrm{i}$ vaixells per accions pirates. Els protocols notarials són fonamentals per a l'estudi d'aquesta qưestió. Altrament, les fonts de l'administració reial proporcionen notícies molt diverses: legislació reguladora de la guerra de cors, armaments d'embarcacions corsàries, legislació repressora de la pirateria, reclamacions de mercaders perjudicials, etc. En les fonts locals es pot trobar també certa informació d'aquest tipus, relacionada amb captius, hòmens forçats a galeres $O$ avisaments costaners, entre altres.

2 Des de l'últim terç del segle XV, com a mínim, foren arreplegats aquests avisos en els llibres de Lletres Missives, tot obeint un patró semblant que no canvià amb el pas del temps. El primer avisament que hem trobat nosaltres és del tenor següent:

A.E.M., $20(199$ ') 
podem conèixer, a grans trets, la freqüència de la presència pirata en aquests mars $i$ els seus principals objectius. També, en virtut seva, som capaços de detectar el tipus de vaixell emprat en les incursions, la seua procedència, quins mars foren els preferits pels enemics i tota altra gamma de detalls interessants, connectats amb la natura dels diferents gèneres de pirates o corsaris rivals. Convé deixar constància, això sí, que és molt probable que no tots els avisaments foren enregistrats en els llibres de Lletres Missives; bastants, segurament, no meresquen l'atenció de l'escrivà corresponent $\mathrm{i}$ es perdé la constatació de llur existència ${ }^{3}$. Per aquesta raó, la font no pot entendre's com un instrument facilitador d'uns resultats rigorosos de recompte quantitatiu. Així, encara que usualment se segueixen els mateixos criteris de redacció de les notes d'avís, no pas en tots els casos s'atribueix importància a alguns conceptes que integren el que podríem anomenar l'avisament tipus o patró ${ }^{4}$. No obstant això, la detecció de l'activitat pirata en aquestes aigües depèn, en un alt percentatge, d'aqueixos avisos que esdevenen imprescindibles a l'hora de fixar-hi la intensitat, per exemple, de la presència islàmica.

\section{ELS AVISAMENTS COSTANERS SOBRE ELS PIRATES MUSULMANS: 1480-1520}

Entre els anys 1480 i 1520 trobem 230 albiraments, dels quals almenys 149 $(64,78 \%)$ corresponen a vaixells islàmics. Aquesta xifra pogué ésser major, ja que manquem d'informacions per al sexenni 1490-1495 i per als anys 1510-1512. Altrament, cal pensar que un bon nombre dels avisos, en els quals no s'esmenta l'origen dels pirates, hagué d'ésser relatiu a corsaris sarraïns. Hi ha 51 casos en què ignorem la procedència dels enemics i que equivalen al $22,17 \%$ del total. Per últim, convé no menysprear el desconegut percentatge d'aquells albiraments que no foren arreplegats en la documentació municipal de manera conscient o per oblit de l'escrivent corrersponent'. Malgrat tot, les dades de les quals disposem són suficients

"Als honrats e discrets los justícia e jurats de la vila de Morvedre. De Nós, los jurats de la ciutat de Valencia, Salue e honor.

Certificam-vos, ara de present, haven reebuda una letra dels jurats e prohòmens de la ylla d'Iviça, en la qual n.s han fet saber que divendres prop passat, en hora de prima son, una galea e una galiota de moros foren a Portmany, de la dita ylla, e feriren en la Vayll de la Ecclesia de Sent Anthoni e alli feren gran dan. E on vos certificam de les dites coses perquè siacs en bona guarda que dan o mal no puxars pendre per les dites galea e galiota e escrivets d'aquest fet a vostres primers vehíns de la marítima per tal que d'ùns en altres puxa ésser sabut prestament e dats al portador de la present son salari quatre sous.

Scrita en Valencia, dimarts hora de vespres sonants a XXV dies de juliol del any de la Nativitat de Nostre Senyor M CCC LXXIIII.

Semblant letra fon tramesa als honrats los justicia e jurats de la vila de Cullera. E que donen al portador d'aquella cinch sous."

Arxiu Municipal de Valencia (AMV), Lletres Missives, $8^{3}-3$, f. 36 r.

3 L'll de juliol de 1496, per exemple, s'escrivia una carta d'agralment a la vila d'Eivissa per l'avís que el patró de lladt Joan Fullana havia dut a Valencia el dia 7 del mateix mes.S hi comunicava, igualment, el pagament de 10 lliures per aquest servei. AMV, Lletres Missives, $8^{3}-33, f .15$ v. Aquesta lletra tambe feia referència a una altra notícia identica arribada a València pel sistema d'avisaments costaners. Ni el text que porta Joan Fullana ni el que vingué a través de xarxa d'alertes no $s$ 'han conservat.

4 Cf. notes $13,14,18,22,23,31,33,43,47,49,51,53,54,55,58,60,62$ y 68, per exemple.

5 Els llibres de Lletres Missives revisats han segut: $8^{3}-29$, que comprenen els anys 1478-1481; $8^{3}-30$, 1481-1484; $B^{3}-31$, anys $1485-1488 ; B^{3}-32$, anys $1488-1489 ; g^{3}-33$, anys $1496-1502 ; B^{3}-34$, anys $1502-1505$; $\mathbb{B}^{3}-35$, anys $1505-1508 ; B^{3}-37$, anys $1509-1511 ; B^{3}-38$, anys $1511-1514 ; g^{3}-39$, anys $1514-1516 ; B^{3}-40$, anys 1516-1518 i $8^{3}-41$, anys $1518-1521$. 
per a establir un balanç de la tendència de llarga durada que es devia remuntar fins al segle XIV. Precisament, gràcies al fet que som capaços de tornar en el temps fins als començaments del fenomen pirata, podem analitzar i comprendre millor les seues fases posteriors. En aquest sentit, a través de les notificacions procedents del sistema d'avisos podem apreciar quatre etapes prou ben delimitades:

1) 1370-1430. Si al llarg de tot els tres-cents la presència de la pirateria islàmica en aigües catalanes fou limitada i esporàdica, des de l'últim terç del segle XIV, el percentatge de localitzacions d'embarcacions de pirates musulmans, en comparança al de cristians, representa unes estadístiques molt superiors al $50 \%$ i assoleix en alguns decennis índexs per damunt del $90 \%$ del total.

2) 1430-1470. En aquest període, s'hi aprecia una disminució relativa a la pressió islàmica que es tradueix en una davallada considerable de la seua participació puntual sobre el total dels albiraments. Mai no s'arribarà a valors propers al $50 \%$, sempre dins d'una tònica depressiva que va del 48 al $13 \%$ en els decennis límit.

3) 1470-1500. Les dècades finals del segle' XV contemplaran una diàfana tendència a la resistència en la recessió observada per al període anterior. Per tant, de valors pròxims al $13 \%$ es passarà a percentatges que s'acostaran al $30 \%$.

4) 1500-1520. Serà en aquesta època quan es definesca més clarament la pressió sarraïna sobre les costes de la Confederació. Els albiraments d'enemics musulmans hi arribaran fins a la significativa xifra del $75 \%$ del total de la mitjana per a l'etapa.

\section{QUADRE I}

\section{ALBIRAMENTS DE VAIXELLS MUSULMANS, 1370-1520}

\begin{tabular}{|c|c|c|c|c|c|c|c|}
\hline $1370-79$ & 11 & d'un total de & 12 & albiraments, & equivalents & al 91,66\% & del total. \\
\hline $1380-89$ & 39 & & 41 & n & n & $95,12 \%$ & \\
\hline $1390-99$ & 35 & n & 40 & $n$ & " & $87,50 \%$ & $n$ \\
\hline $1400-09$ & 22 & $n$ & 26 & n & $n$ & $84,61 \%$ & $n$ \\
\hline $1410-19$ & 55 & n & 68 & n & $n$ & $80,88 \%$ & $"$ \\
\hline $1420-29$ & 47 & $n$ & 60 & $n$ & n & $78,33 \%$ & n \\
\hline $1430-39$ & 12 & n & 25 & $n$ & n & $48,00 \%$ & n \\
\hline $1440-49$ & 13 & $n$ & 40 & n & " & $32,50 \%$ & $n$ \\
\hline $1450-59$ & 37 & $n$ & 137 & n & n & $27,00 \%$ & \\
\hline $1460-69$ & 4 & " & 29 & " & n & $13,79 \%$ & $n$ \\
\hline $1470-79$ & 20 & n & 67 & n & n & $32,83 \%$ & n \\
\hline $80-89$ & 7 & $n$ & 20 & $n$ & " & $35,00 \%$ & n \\
\hline $90-99$ & 11 & n & 37 & n & n & $29,72 \%$ & \\
\hline $0-09$ & 84 & n & 99 & $n$ & $"$ & $88,88 \%$ & n \\
\hline $1510-19$ & 47 & $n$ & 74 & $n$ & $"$ & $63,51 \%$ & \\
\hline
\end{tabular}

FONTS: Arxiu Municipal de València (AMV), Lletres Missives, $g^{3}-1$ al $g^{3}-33$. 
Vid. igualment els següents treballs on es donen noves aportacions en aquesta qüestió. Andrés DÍAZ BORRÁS,, Redención de cautivos y piratería berberisca en la Valencia del siglo XIV, Tesi de llicenciatura llegida a València, 1983. Rafael CARIÑEna BALAGUer, i Andreu DíAz BORRÁs, Corsaris valencians i esclaus barbarescs a les darreries del segle XIV: una subbasta d'esclaus a València el 1385, "Estudis Castellonencs», 2 (1984-85), págs. 439-456. Andrés DíAZ BORRÁS. Problemas maritimos de Valencia a fines de la Edad Media: el corso, la pirateria y el cautiverio en su incidencia sobre la dinámica económica, 1400-1480, Tesi doctoral microfitxada, València, 1987.

Totes aquestes dades no tenen un mer abast especulatiu, atès que es veuen corroborades, en cadascun dels casos, per una veritable tendència històrica dominant. En efecte, el primer període correspon al moment en què comença a detectar-se en el litoral valencià la presència islàmica de manera sistemàtica, $i$ que experimentarà una relativa intensitat inicial molt important ${ }^{6}$. La segona etapa, coincideix amb la fase on la gran proliferació de la pirateria cristiana, de mitjan segle XV, desplaçarà les agressions sarraines a un pla secundari tot posant, altrament, en greus dificultats el comerç marítim de la capital valenciana '. La tercera època es connecta amb un període de transició, replantejament i regeneració de les activitats pirates musulmanes. És el moment en què apareixen anotats els primers atacs turcs, els quals, en un proper futur, tindran una influència primordial en el suport del cors barbaresc. En aquest sentit, si durant el terç final del segle XIV i una bona part del quatre-cents, els vaixells corsaris granadins $i$ la infrastructura portuària del regne nassarí resultaven de vital importància, a hores d'ara aqueix paper serà jugat per la creixent intervenció turca ${ }^{8}$. Finalment, la quarta fase es correspondrà amb el moment de màxima virulència de les accions pirates sarraïnes, que assoliran una ressonància força més accentuada que en èpoques anteriors. El salt qualitatiu que suposà, per exemple, l'atac a la població de Cullera, propera a la capital valentina, l'any 1503 , serà significatiu i endemés deixarà una profunda petjada entre la societat valenciana ?.

Tot seguit, repassarem les característiques fonamentals que perfilaren el fenomen de la pirateria musulmana en la transició a la modernitat, és a dir, entre els anys 1480 i 1520.

Del bell antuvi i pel que toca a la procedència dels avisaments, caldrà tenir en compte la interrelació, que no assimilació, entre la xarxa de comunicacions costane-

- Andreu IVARS CARDONA, Duas creuades valenciano-mallorquines a les costes de Berberia, 1397-1399, València, 1921. Andrés DÍAZ BORRÁS, Redención de cautivos y piratería berberisca en la Valencia del siglo XIV, Tesi de llicència llegida a València, 1983.

' Andrés DíAZ BORRÁs, Problemas marítimos de Valencia a fines de la Edad Media: el corso, la pirateria y el cautiverio en su incidencia sobre la dinámica económica, 1400-1480, València, 1988, Edic. microfitxada.

8 Sobre el començament de la presència pirata turca en aigües peninsulars vid. Anna MASALA, La prima spedizione ottomana in Spagna (1487), «Medioevo. Saggi e Rassegne», 8 (1983), págs. 119-135. D'una altra banda, durant els anys 1989 i 1989, sota la direcció del Doctor En Josep Trenchs Òdena, forem becats per la Comisión Interministerial de Ciencia y Tecnología, dintre del programa de formació de personal investigador, integrats en la línia de treball Espatia y el Mundo Árabe, per tal d'analitzar el tema: La documentación maritima valenciana y Berberia en la Era de los Descubrimientos (1480-1520). Un ejemplo de la decadencia de la Corona de Aragón en la transición del Mediterráneo al Atlántico.

9 Andrés DíAZ BORRÁs, El asalto berberisco a Cullera en 1503 y Alzira en la defonsa de la Ribera, "Al-Gezira", 4/5 (1988), págs. 147-172. 
res i el sistema de vigilància litoral. Si aquest segon aspecte ha estat mereixedor d'estudis parcials $\mathrm{i}$ algun intent generalitzador, el primer punt és pràcticament desconegut. La ciutat de València devia estar integrada en una xarxa d'intercanvi de comunicacions que devia tenir com a enllaços immediats les poblacions de Morvedre, al nord, Cullera, al sud, i les ciutats de Mallorca o Eivissa, a l'est. A més a més, el sistema d'avisos segurament abraçava també les lletres i notificacions provinents de les embarcacions amigues o dels mercaders en terres estrangeres, que devien proporcionar notícies sobre els moviments dels pirates islàmics. Pertocant a aquest últim aspecte, cal dir que la constatació i la provinença d'aquests avisaments és difícil de delimitar i que, dintre la norma general, representaven una excepció. Per finalitzar aquesta qüestió, cal afegir-hi que també haurem de tenir present els avisos que, en circumstàncies molt concretes, s'enviaran mitjançant correus especials des de les principals ciutats costaneres de la Corona d'Aragó: Barcelona, Tarragona, Tortosa o València.

Altrament, són molt significatives, en referència al cors musulmà, les informacions, freqüentment inserides en les notes d'alarma, les quals ens parlen dels tipus de vaixells utilitzats pels enemics. Hem de remarcar, en el cas que ens ocupa, que tots els avisaments fan esment a fustes de rems, puix que el grip, com les galeres o galiotes, àdhuc posseint velam, anava impulsat per la força dels rems. En alguns casos, la font ens dóna, específicament, les característiques de les embarcacions descobertes, quasi sempre galiotes o fustes de menor tamany, és a dir, d'uns 13 o 14 bancs. La galera fou un vaixell poc emprat $i$ açò és simptomàtic de les carències financeres dels armadors barbarescs. Respecte d'això, cal ressenyar que, en aquest període en qüestió, ja havien irromput des de temps enrere uns altres tipus de navilis, i cada dia apareixien en el sistema d'avisos referències a nous models, que abandonaven la propulsió del rem per la de la vela. Semblant absència explica la inadaptació, encara latent, de la marina nord-africana a la guerra naval, fet que palesa un substancial endarreriment en comparança als estols cristians de l'època. A més, aquesta trigança tingué com a seqüela el progressiu estanyament dels tipus de vaixells utilitzats $i$ una miniaturització dels models emprats, en contrast amb etapes immediatament anteriors ${ }^{10}$.

Com és lògic, la component barbaresca és àmpliament majoritària entre la pirateria musulmana del període. En aquest context, les fonts sempre anomenen aquests corsaris com a moros; per tant, és impossible distingir-los dels granadins, encara que és factible intuir que, en els darrers anys d'existència del regne nassarí, llur activitat era força reduïda. Molt més rellevant és la detecció de corsaris otomans

10 Sense intentar esgotar l'extensa relació de treballs relatius a la xarxa de vigilància litoral valenciana podem citar, entre altres: Luís QUEROL ROSO, Las milicias valencianas desde el siglo XIII al XV, Castelló de la Plana, 1935. Francisco G. SEIJO ALONSO, Torres de vigla y defensa contra los piratas berberiscos en la costa del reino de Valencia, Alacant, 1978. José María DOÑATE SEBASTIA, La torre del rey, notas para el estudio de la piratería musulmana en el litoral, «Datos para la historia de Villarreal», II, València, 1972, págs. 12-79. Alfredo AYZA ROCA, La Madum, pirateria y defensa del litoral valenciano, «Peñíscolan, 55 (1982), págs. 2-7. Ferran OLUCHA MONTIS, Sobre unes corros de dofensa litoral, «Estudis Castellonencsn, 2 (1984-85), págs. 145-162. Vicente, FORCADA MARTí, La torre del Rei, «Boletín de la Sociedad Castellonense de Cultura», 64 (1988), págs. 359-399. A penes algunes referències en el llibre de Luis Querol, citat abans i en el d'Andreu Ivars. Vid. nota S, ens il-lustren sobre el sistema de comunicacions costaneres. Per altre costat, Julián Amich defineix el gripo com a una Antigua embarcación de carga impulsada por vela o remos. Julián AMICH, Diccionario marítimo. Barcelona, 1983, págs. 213. 
en les aigües valencianes; per exemple, l'any 1498 trobem la primera referència explícita de llur albirament, tot fent-hi la distinció entre turcs i moros. Probablement, els pirates turcs ja devien actuar-hi des d'alguns anys abans, això sí, en col-laboració amb els nord-africans".

L'impuls otomà ha d'ésser considerat com a essencial per a la supervivència de l'activitat marítima corsària. A més a més, junt al recolzament polític i al rearmament ideològic que suposarà, servirà també per a assajar alternatives més eficaces enfront de l'evident endarreriment tecnològic musulmà. En aquest marc, l'emprament del grip -primera referència d'aquest tipus d'embarcació anotada en els avisaments costaners - tal vegada fou simplement una prova de la recerca d'un navili petit, barat i competitiu, de vela, que cristal litzarà anys després amb l'adaptació del xabec a la guerra naval. Els llocs de localització són clarament perfilats. Així, doncs, deixant a banda les notícies que ens parlen de vaixells descoberts en zones barbaresques, disposats a recórrer aquestes aigües, la resta es concentrarà en els mars alacantins, $i$ castellonencs en menor grau. Respecte d'això, podem afirmar que no existeix cap variació pel que fa a temps passats ${ }^{12}$. En aquest aspecte convé, això sí, fer un parell de puntualitzacions. La primera és constatar l'escassa incidència de la pirateria musulmana en aigües de Catalunya i Balears, la qual cosa és, en certa mesura, sorprenent, més en el cas de les illes que en el del principat. Aquest fenomen podríem atribuir-lo, en una gran part, a la dissolució de la solidaritat marítima catalana, com a factor enterbolidor de la lliure circulació d'avisos costaners, però, sense llevar importància a aquesta realitat, creem que la pròpia dinàmica de la presència islàmica en aquests mars és la raó fonamental que cal tenir en compte. Sobre aquesta qüestió, podem suggerir que els pirates barbarescs tendien a sentir-se més còmodes i segurs amb la utilització de la ruta de l'Estret -vorejant el nord d'África per a fer posteriorment un petit salt i passar al costat peninsular mediterrani- que no amb l'emprament de la ruta directa des de Barbaria vers les Balears i València. La raó que sustenta de aquesta hipòtesi pot ser, bàsicament, la temença dels corsaris als perills que devien ocasionar els enfrontaments en mar obert amb fustes força menudes. La segona puntualització es refereix a la tradicional manera d'actuar d'aquests pirates, mitjançant els assalts a terra o la capció d'embarcacions petites $\mathrm{i}$ mals preparades per a oferir una aferrissada resistència. Els atacs a les poblacions de Cullera i Orpesa hem d'entendre'ls com a fets molt greus i poc frequients, puix que Cullera, per exemple, era una localitat suficientment gran com per a repel lir una agressió marítima d'aquesta índole. De fet, els pirates musulmans mai, fins aleshores, no s'havien atrevit a escometre l'arriscada empresa que suposava l'arremesa al port auxiliar de la ciutat de València. Quant al cas d'Orpesa, és significatiu per l'enorme transcendència que tingué en el moment de produir-se, quasi un segle després del saqueig de la vila de Torreblanca. Per últim, cal fer esment sobre l'època de l'any en què s'hi produïren els albiraments pirates. Certament, els

11 Aixf l'any 1491, per exemple, es pagaven 50 sous a dos individus de la població de Teulada per portar els caps do monas o turcbs, los quals ban passat a la prosent ciutat, los quals són stats morts en Morayra de una fustra de monas a surcbs. AMV, Manuals de Consells, A-46, f. 96 r.

12 Jose HINOJOSA MONTALVO, Pirabas y corsarios on la Valoncia do principios dol siglo XV, (1400-1409), «Cuadernos de Historiaw, 5 (1975), págs. 93-116. 
vaixells baixmedievals ja es trobaven en condicions de navegar en qualsevol estació de l'any, amb una dotació de mariners mitjanament competent; però, sobretot, per a les embarcacions islàmiques, el final de la primavera, l'estiu i el començament de la tardor, constituiran les èpoques indicades per la bonança de la mar.

\section{ELS AVISAMENTS COSTANERS SOBRE ELS PIRATES CRISTIANS: 1480-1520}

Dels susdits avisos trobats per al període 1480-1520, n'hi ha 30 (equivalents al $13,04 \%)$ que corresponen al cors cristià. Hem de remarcar, especialment, pel que toca a la pirateria cristiana, que un percentatge força alt dels avisaments d'enemics desconeguts correspondrà a corsaris correligionaris. Així, doncs, una gran part del 22,17\% que representà aquesta amenaça indefinida seràn cristians; aquesta deducció es basa en el tipus d'embarcacions, el nombre d'unitats i llur manera d'actuar, dades que encaixen millor en la trajectòria de la marina cristiana que en la musulmana.

En el Quadre I exposàvem l'evolució secular del cors islàmic en relació al cristià. D'aquest quadre podem extraure una sèrie de conclusions relatives a les fases d'expansió i contracció dels diferents tipus de pirates. Si ens remuntem en el temps fins al segle XIV, distingim una successió d'etapes en les quals apreciem el divers grau d'intensitat de la presència dels distints gèneres de corsaris. Tot seguit, exposarem, en el Quadre II, la visió panoràmica de la incidència pirata cristiana, segons períodes, des del segle XIV fins a l'època objecte del nostre estudi. Així, podrem apreciar i percebre la importancia del cors cristià segons la seua procedència.

\section{QUADRE II}

\section{ALBIRAMENTS DE VAIXELLS CRISTIANS, 1330-1520}

$\begin{array}{lccccr}\text { Decennis. } & \text { Genovesos. } & \begin{array}{c}\text { Provençals o } \\ \text { Francesos. }\end{array} & \text { Altres. } & \text { Desconeguts. } & \text { Total. } \\ 1330-39 & 1(100 \%) & - & - & - & 1 \\ 1340-49 & 4(80 \%) & - & 1(20 \%) & - & 5 \\ 1350-59 & 16(100 \%) & - & - & - & 16 \\ 1360-69 & - & - & - & - & - \\ 1370-79 & - & 1(8,33 \%) & - & - & 12 \\ 1380-89 & - & - & - & 2(4,87 \%) & 41 \\ 1390-99 & 2(5 \%) & - & - & 7(7,50 \%) & 40 \\ 1400-09 & 1(3,84 \%) & - & - & 3(11,53 \%) & 26 \\ 1410-19 & 7(10,29 \%) & - & - & 6(8,82 \%) & 68 \\ 1420-29 & 9(15 \%) & - & - & 4(6,66 \%) & 60 \\ 1430-39 & 9(36 \%) & 1(4 \%) & 1(4 \%) & 2(8 \%) & 25 \\ 1440-49 & 13(32,50 \%) & 9(22,50 \%) & 2(5 \%) & 3(7,50 \%) & 40 \\ 1450-59 & 13(9,48 \%) & 31(22,62 \%) & 25(18,24 \%) & 31(22,62 \%) & 137 \\ 1460-69 & 4(13,79 \%) & 5(17,24 \%) & 13(44,82 \%) & 3(10,34 \%) & 29 \\ 1470-79 & 1(1,49 \%) & 12(17,91 \%) & 20(32,83 \%) & 14(20,89 \%) & 67 \\ 1480-89 & 8(40 \%) & - & - & 5(25 \%) & 20 \\ 1490-99 & - & 15(40,54 \%) & - & 11(29,72 \%) & 37\end{array}$


Decennis. Genovesos. Provençals o Altres. Desconeguts. Total.

Francesos.

$\begin{array}{cccccc}1500-09 & 1(1,01) & 2(2,02 \%) & - & 12(12,12 \%) & 99 \\ 1510-19 & - & 3(4,05 \%) & 1(1,35 \%) & 23(31,08 \%) & 74\end{array}$

FONTS: A més de Lletres Missives, vid. Quadre I, hem hagut de recórrer a unes altres fonts de l'Arxiu Municipal de València, per al període 1330-1369. AMV, Manuals de Consells, A-1 a l'A-22. Claveria Comuna, O-1 a l'O-3. Claveria Comuna. Manuals d'Albarans. J-1 al J-23. Claveria Comuna. Manuals d'Albarans i Censals, I-1 al I-22.

El primer fet que cal subratllar, dels resultats proporcionats pel Quadre II, és el canvi de la preponderància pirata cristiana de mans dels genovesos a mans dels francesos. Les fonts havien anat fins llavors anomenant provençals els corsaris marsellesos $\mathrm{i}$ de les riberes mediterrànies de França, tot emprant el terme de francesos per als enemics del litoral atlàntic d'aquest país -els quals en singulars ocasions acudiren a recórrer les mars catalano-aragoneses- $\mathrm{i}$ per als súbdits del duc de Borgonya. En la dècada dels 90 , del segle XV, començarà a guanyar crèdit una tendència segons la qual el concepte "francesos» unificarà la diversitat existent fins aleshores. Des d'aqueixos moments, en inusuals ocasions i per un reduit espai de temps, reapareixerà el vocable de provençals.

En aquest context, cal dir que l'evolució secular sempre havia mantingut els pirates genovesos per davant de llurs competidors provençals; però nogensmenys, aquesta propensió es trencarà en allò que podem considerar un canvi històric, entre els anys 1450 i 1470 . En qualsevol cas, després del breu lapse de la dècada dels 80 el domini francès serà preponderant. De faisó que, sense anar més lluny, en el decenni del 1490 es convertiran en els principals enemics de la Corona d'Aragó, en el terreny marítim, per davant inclús dels corsaris sarraïns. Per consegüent, la rivalitat entre ambdós països quedarà patentitzada en els primers dos decennis del cinc-cents, baldament sia, això sí, en uns nivells molt secundaris, amb les reserves generades pels elevats percentatges d'albiraments de navilis desconeguts.

Quant al cors genovès, que ja havia estat present en les mars valencianes des de la meitat del segle XIV, gairebé sense interrupció (vid. Quadre II), direm que disputà durant molt de temps la supremacia a la pirateria musulmana. Encara, en la dècada de 1480-89, s'hi trobava en una posició privilegiada tot superant els pirates islàmics. Tanmateix, molt prompte s'hi va produir una alteració substancial que duria els francesos a rellevar els ligurs en el decenni següent. Per una altra banda, podem veure-hi una disminució força important del cors d'altres potències cristianes, que restarà reduït a nivells purament testimonials. Pel que pertoca a l'apartat dels vaixells enemics desconeguts, es mantindrà en uns percentatges considerables, probablement a causa de la dificultat de concretar llur filiació per part dels sentinelles costaners, com també per la indefinició dels redactors de les notes d'avís que no devien considerar rellevant especificar-ho. 
Finalment, cal remarcar que una bona part dels pirates castellans, portuguesos i d'altres procedències no foren detectats pel sistema d'alerta litoral, atès que aquests eren considerats com a pertanyents a països aliats o neutrals.

Molt interessant és comprovar, també, el tipus d'embarcacions utilitzat pels corsaris. En aquest sentit, els pirates genovesos empraran, com fins llavors havia estat usual en llurs empreses, les galeres i galiotes, fustes del mateix model que les usades pels musulmans, però, generalment, de molta més envergadura i potència. Ara bé, independentment d'aquests fets, mai no desdenyaren la utilització de vaixells de vela o mixtos: naus que els ligurs venien emprant des de molt antigament en els estols comercials, i entre les quals hem d'assenyalar els baleners, bergantins i les barques (naus modificades i freqüentment de menor tamany). Amb tot, podem pensar que les armades dels corsaris ligurs, sense perdre l'eficàcia ofensiva a la qual tenien acostumats els valencians, anaven perdent posicions en comparança a algunes altres potències que, a hores d'ara, començaven a integrar en llurs esquadres uns tipus d'embarcacions més modernes. Respecte d'això, el cas francès és exemplar, ja que, sense ésser una potència puntera en l'àmbit naval, els seus estols estaran formats per una diversa gamma de models de navilis -sense que, per això, predominaren absolutament els de vela o els moguts mitjançant els rems- amb clars símptomes de modernització.

\section{QUADRE III}

\section{ALBIRAMENT DE VAIXELLS ENEMICS, 1480-1520}

NOTA. PROCEDĖNCIA.

(13) Morvedre

(14) Cullera

(15) Morvedre

(16) Morvedre

(17) Eivissa

(18) Desconeguda

(19) València

(20) Desconeguda

(21) Barcelona

(22) Barcelona
TIPUS DE VAIXELL. ENEMICS. LOCALITZACIÓ. DATA.

2 baleners Desconeguts Cap de Benicàssim 1480/03/29.

1 caravel la

Desconegurs Cap de Martí 1480/05/21.

1 galiota de 14 bancs Moros Sitges 1480/06/07.

1 galiota Moros Orpesa 1480/06/09.

1 galera Genovesos Eivissa 1480/06/11.

2 galeres Desconegurs Desconeguda 1480/02/19.

Nombre indeterminat Genovesos València 1481/07/28. de galeres

3 galeres Genovesos València 1482/07/10.

2 galeres i 1 galiota Genovesos Barcelona 1482/07/23.

2 naus grosses i 2 naus Desconeguts Barcelona 1482/09/11.

13 AMV, Lletres Missives, $g^{3}-29$, f. 200 r.

14 Ibidem, f. $210 \mathrm{v}$.

15 Ibidem, f. 215 v.

16 Ibidem, f. $215 \mathrm{v}$.

17 Ibidem, f. $218 \mathrm{v}$.

18 Ibidem, f. 298 v.

19 AMV, Lletres Missives, $8^{3}-30$, f. 17 r.

20 Ibidem, f. 88 r.

21 Ibidem, f. 81 v.

22 Ibidem, f. 99 r. 
NOTA. PROCEDÈNCIA. TIPUS DE VAIXELL. ENEMICS. LOCALITZACIÓ. DATA.

(23) Cullera Fusta de 13 o 14 bancsDesconeguts Teulada 1483/08/28.

(24) Barcelona

4 galeres, 1 nau i 1 barca Venecians i Barcelona

$1483 / 10 / 11$.

(25) Cullera

genovesos

(26) Cullera

3 naus i 2 bergantins

Genovesos

2 galiotes

Moros

Cullera

$1484 / 07 / 15$.

(27) Mallorca

9 fustes

Moros

Altea

$1484 / 08 / 30$.

(28) Mallorca

7 galiotes

Moros

Tunis

$1485 / 06 / 23$.

(29) Eivissa

3 naus grosses, 1 balener Genovesos

Tunis

$1485 / 09 / 05$.

i 3 bergantins

(30) Eivissa

1 galera i 1 bergatí

Genovesos

Eivissa

$1486 / 05 / 30$.

(31) Desconeguda

Nombre indeterminat Moros

Eivissa

$1487 / 08 / 11$. de fustes

(32) Morvedre-Barcelona 21 fustes sotils i 1 grossa Moros Argel

$1489 / 05 / 29$.

(33) Cullera

3 galeres

Desconeguts Dénia

$1489 / 06 / 07$.

(34) Cullera

4 naus $i$ i bergantí

Francesos Xabia

$1496 / 05 / 24$

(35) Eivissa

1 nau i 1 bergantí

Francesos Eivissa

$1496 / 05 / 31$.

(36) Morvedre

6 fustes de gàbia

Francesos

1496/06/01.

(37) Cullera

(38) Morvedre

4 fustes

Moros

Peníscola

$1496 / 06 / 01$.

5 galeres $i$ altres vaixells Francesos

El Pinatar

1496/08/04.

3 naus

Francesos

Provença

$1496 / 09 / 23$.

7 fustes i 3 naus Francesos

Almeria

$1496 / 10 / 08$.

(40) Morvedre

4 o 5 fustes, 2 naus, 1 Francesos

Alcosséber

1496/11/10. galió i 1 caravel la.

(42) Cullera

(43) Cullera

1 nau i 1 caravel.la

Francesos Cap de Martí

1496/11/25.

4 naus

Desconeguts Cap de Martí

$1496 / 11 / 25$.

1496/12/05.

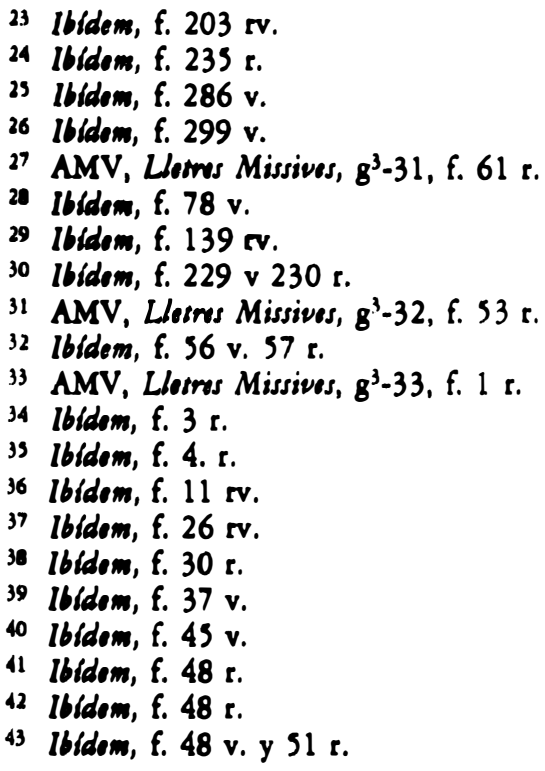


NOTA. PROCEDĖNCIA. TIPUS DE VAIXELL. ENEMICS. LOCALITZACIÓ. DATA.

\begin{tabular}{|c|c|c|c|c|c|}
\hline \multirow[t]{2}{*}{ (44) } & \multirow[t]{2}{*}{ Cullera } & \multirow[t]{2}{*}{2 galeres } & \multicolumn{3}{|l|}{ Moros o Fran- } \\
\hline & & & cesos & Moraira & $1496 / 12 / 21$. \\
\hline (45) & Cullera & Caravel-la i balener & Francesos & La Granadella & 1497/05/31. \\
\hline (46) & Morvedre & 2 fustes & Moros & Benicàssim & 1497/06/03. \\
\hline (47) & Morvedre & 5 naus & Desconeguts & Cabrera & 1497/06/10. \\
\hline (48) & Morvedre & 2 galiotes & Moros & Mallorca-Menorca & $1497 / 06 / 10$. \\
\hline (49) & Morvedre & 1 fusta & Desconeguts & Cap d'Orpesa & 1497/08/03. \\
\hline (50) & Morvedre & 1 nau i 1 barca & $\begin{array}{l}\text { Francesos i } \\
\text { castellans }\end{array}$ & Peníscola & 1497/08/09. \\
\hline$(51)$ & Desconeguda & 3 galeres i 1 galió & Francesos & Marsella & $1497 / 10 / 02$ \\
\hline (52) & Eivissa & Barca de 850 botes & Francesos & $\begin{array}{l}\text { Cap de Martí-Cap } \\
\text { Vedrà }\end{array}$ & $1497 / 10 / 03$. \\
\hline (53) & Cullera & 4 navilis & Desconeguts & Cap de Moraira & $1498 / 02 / 02$. \\
\hline (54) & Morvedre & 2 fustes & Desconeguts & Salou & 1498/03/07. \\
\hline$(55)$ & Morvedre & 2 barques & Desconeguts & Salou & 1498/04/09. \\
\hline (56) & València & 11 fuageu & Francesos & València & 1498/05/05. \\
\hline (57) & Cullera & 2 navilis i 2 bergantins & s Francesos & Cap de Martí & $1498 / 05 / 14$ \\
\hline (58) & Cullera & 15 navilis de gàbia & Desconeguts & La Granadella & 1498/05/17. \\
\hline (59) & Morvedre & 1 fusta & Moros & Cap d'Orpesa & $1498 / 06 / 01$. \\
\hline$(60)$ & Cullera & 1 fusta & Desconeguts & Cap de Martí & 1498/06/02. \\
\hline (61) & Eivissa & $\begin{array}{l}3 \text { galeres, } 1 \text { barca i } 1 \\
\text { bergantí }\end{array}$ & Francesos & Eivissa & $1498 / 06 / 26$ \\
\hline (62) & Barcelona & 3 galeres i 2 fustes & Desconeguts & Mataró & $1498 / 07 / 02$. \\
\hline (63) & Eivissa & $\begin{array}{l}2 \text { galeres, } 2 \text { galiotes de } \\
13 \text { y } 18 \text { bancs, } 1 \text { grip }\end{array}$ & Turcs & Bogia & 1498/09/04. \\
\hline 64) & Morvedre & 15 fustes & Moros & Orpesa & 1499/04/04. \\
\hline 65) & Cullera & 1 fusta & Moros & Cullera & $1499 / 06 / 08$. \\
\hline
\end{tabular}

44 Ibidem, f. 53 r.

45 Ibidem, f. 65 v.

46 lbidem, f. $66 \mathrm{v}$.

47 lbidem, f. $70 \mathrm{v}$.

48 Ibidem, f. 70 v.

49 lbidem, f. 80 v.

so Ibidem, f. 81 r.

s1 Ibidem, f. 90 v.

32 Ibidem, f. $90 \mathrm{v}$.

33 lbidem, f. 105 v 106 r.

$\$ 4$ Ibidem, f. $116 \mathrm{r}$.

ss Ibidem, f. $123 \mathrm{r}$.

36 Ibidem, f. $130 \mathrm{r}$.

37 lbidem, f. 131 r.

38 Ibidem, f. 131 v.

s9 Ibidem, f. $133 \mathrm{v}$.

60 Ibidem, f. $134 \mathrm{r}$.

61 lbidem, f. 137 v.

62 Ibidem, f. 139 v.

63 lbidem, f. 150 r.

64 Ibidem, f. 169 v.

65 Ibidem, f. 183 r. 


\begin{tabular}{|c|c|c|c|c|c|}
\hline NOTA. & PROCEDE்NCIA. & TIPUS DE VAIXELL. & ENEMICS. & LOCALITZACIÓ. & DATA. \\
\hline (66) & Morvedre & 1 fusta & Moros & Blanes & $1499 / 06 / 20$ \\
\hline (67) & Cullera & 7 fustes & Moros & Desconeguda & $1499 / 06 / 21$ \\
\hline (68) & Eivissa & 1 balener & Desconeguts & Eivissa & $1499 / 07 / 04$ \\
\hline (69) & Cullera & 1 fusta & Moros & Guardamar & $1499 / 12 / 16$ \\
\hline (70) & Cullera & 12 fustes de gàbia & Moros & Melilla & $1500 / 04 / 01$ \\
\hline (71) & Morvedre & 1 fusta i 1 navili & Desconeguts & Barcelona & $1500 / 04 / 29$ \\
\hline (72) & Morvedre & 1 navili & Francesos & Cap de Martí & $1500 / 05 / 29$ \\
\hline (73) & Morvedre & 1 fusta i 1 bergantí & Desconeguts & Tortosa & $1500 / 06 / 03$ \\
\hline (74) & Cullera & 1 barca i 4 galeres & Genovesos & Marsella & $1501 / 02 / 21$ \\
\hline (75) & Cullera & 2 fustes & Moros & Cullera & $1501 / 03 / 06$ \\
\hline (76) & Cullera & 6 fustes & Moros & Orà i Honein & $\begin{array}{l}1501 \text { sense } \\
\text { data. }\end{array}$ \\
\hline (77) & Cullera & 1 fusta & Moros & $\begin{array}{l}\text { Punta Na Vidala } \\
\text { (Dénia) }\end{array}$ & $1501 / 04 / 02$ \\
\hline (78) & Cullera & 2 fustes & Moros & $\begin{array}{l}\text { Punta Foradada } \\
\text { (Guardamar) }\end{array}$ & $1501 / 04 / 03$ \\
\hline (79) & Cullera & 2 fustes & Moros & Penyes de l'Albir & $1501 / 05 / 25$ \\
\hline (80) & Cullera & $\begin{array}{l}\text { Nombre indeterminat } \\
\text { de fustes }\end{array}$ & Moros & Moraira & $1501 / 06 / 19$ \\
\hline (81) & Algun lloc de Sicília & $\begin{array}{l}\text { a } 1 \text { bergantí, } 13 \text { galeres } \\
3 \text { fustes }\end{array}$ & iTurcs & Palerm & $1501 / 07 / 2$ \\
\hline (82) & Cullera & 6 fustes & Moros & Penyes de l'Albir & $1501 / 08 / 25$ \\
\hline (83) & Cullera & 1 fusta & Moros & La Granadella & $1501 / 12 / 11$. \\
\hline (84) & Cullera & 2 fustes & Moros & Penyes de l'Albir & $1502 / 03 / 10$. \\
\hline (85) & Cullera & 1 fusta & Moros & Cullera & $1502 / 03 / 14$ \\
\hline (86) & Cullera & 1 fusta & Moros & $\begin{array}{l}\text { Punta Plana (Cap } \\
\text { de Martí) }\end{array}$ & $1502 / 03 / 15$ \\
\hline
\end{tabular}

66 Ibidem, f. 187 r.

67 Ibidem, f. 187 r.

68 Ibidem, f. $188 \mathrm{v}$.

69 Ibidem, f. 197 r

70 Ibidem, f. 217 r.

71 Ibidem, f. 219 r.

72 Ibidem, f. $221 \mathrm{v}$.

73 Ibidem, f. 224 v.

74 Ibidem, f. $242 \mathrm{v}$.

75 Ibidem, f. 243 r.

76 Ibidem, f. 249 r.

77 Ibidem, f. 249 v.

78 Ibidem, f. 249 v.

79 Ibidem, f. 251 r.

80 Ibidem, f. 256 r.

81 Ibidem, f. 263 v.

82 Ibidem, f. 269 r.

83 Ibidem, f. 277 v.

84 Ibidem, f. 283 v.

8s Ibidem, f. 284 r.

86 Ibidem, f. 284 v. 


\begin{tabular}{|c|c|c|c|c|c|}
\hline $\begin{array}{l}\text { NOTA. } \\
(87)\end{array}$ & $\begin{array}{l}\text { PROCEDĖNCIA. } \\
\text { Cullera }\end{array}$ & $\begin{array}{l}\text { TIPUS DE VAIXELL. } \\
\text { Nombre indeterminat } \\
\text { de fustes i } 1 \text { bergantí }\end{array}$ & $\begin{array}{l}\text { ENEMICS. } \\
\text { Moros }\end{array}$ & $\begin{array}{l}\text { LOCALITZACIÓ. } \\
\text { Santa Pola }\end{array}$ & $\begin{array}{l}\text { DATA. } \\
1502 / 04 / 04\end{array}$ \\
\hline (88) & Cullera & 6 fustes & Moros & Guardamar & $1502 / 04 / 09$ \\
\hline (89) & Cullera & 6 fustes & Moros & El Pinatar & $1502 / 05 / 12$ \\
\hline (90) & Cullera & 1 fusta & Moros & Penyes de l'Albir & $1502 / 05 / 27$. \\
\hline (91) & Cullera & 12 fustes & Moros & Màlaga & $1502 / 05 / 27$ \\
\hline (92) & Morvedre & 3 fustes & Moros & Borriana & $1502 / 06 / 02$. \\
\hline (93) & Eivissa & 4 fustes & Moros & Ciutadel $\cdot$ la & $1502 / 06 / 03$. \\
\hline (94) & Cullera & 2 fustes & Desconeguts & Penyes de l'Albir & $1502 / 06 / 03$. \\
\hline (95) & Cullera & 2 fustes & Desconeguts & Xeraco & $1502 / 07 / 15$ \\
\hline (96) & Morvedre & 2 fustes & Moros & La Ràpita & $1502 / 09 / 07$. \\
\hline (97) & Cullera & 1 fusta & Moros & Xàbia & $1503 / 03 / 28$ \\
\hline (98) & Alacant & 3 fustes & Moros & Penyes de l'Albir & $1503 / 04 / 10$. \\
\hline (99) & Cullera & 4 fustes & Moros & Altea & $1503 / 04 / 12$. \\
\hline (100) & Cullera & 1 fusta & Moros & Cap de Martí & $1503 / 04 / 13$. \\
\hline (101) & Cullera & 11 fustes & Moros & Escombreras & $1503 / 05 / 18$ \\
\hline (102) & Cullera & $\begin{array}{l}\text { Estol de més de } 100 \\
\text { fustes }\end{array}$ & Moros & Cartagena & $1503 / 05 / 31$. \\
\hline (103) & Cullera & 1 fusta & Moros & Calp & $1503 / 06 / 16$ \\
\hline (104) & Morvedre & 2 fustes & Moros & Alfacs & $1503 / 07 / 19$ \\
\hline (105) & Cullera & 1 fusta & Moros & La Granadella & 1503/07/19. \\
\hline (106) & Cullera & 1 galiota & Desconeguts & Cap de Cullera & $1503 / 09 / 21$. \\
\hline (107) & Cullera & 7 fustes & Moros & Cartagena-Gandia & $1503 / 10 / 07$ \\
\hline (108) & Rei Ferran & $\begin{array}{l}5 \text { galeres i altres } \\
\text { grans vaixells }\end{array}$ & Francesos & Sud de França & $1503 / 10 / 15$. \\
\hline
\end{tabular}

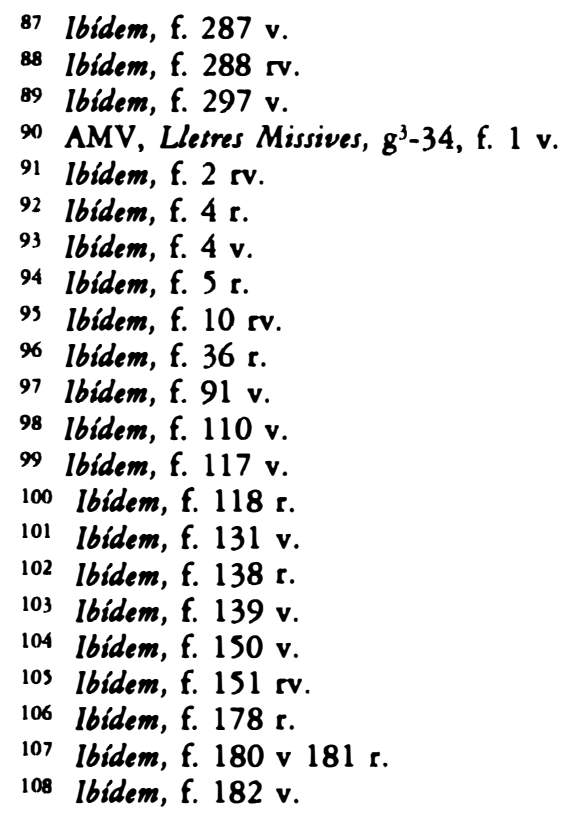




\begin{tabular}{|c|c|c|c|c|c|}
\hline $\begin{array}{l}\text { NOTA. } \\
\text { (109) }\end{array}$ & $\begin{array}{l}\text { PROCEDĖNCIA. } \\
\text { Cullera }\end{array}$ & $\begin{array}{l}\text { TIPUS DE VAIXELL. } \\
\text { Nombre indeterminat } \\
\text { de fustes }\end{array}$ & $\begin{array}{l}\text { ENEMICS. } \\
\text { Moros }\end{array}$ & $\begin{array}{l}\text { LOCALITZACIÓ. } \\
\text { Cap de Negret } \\
\text { (Altea) }\end{array}$ & $\begin{array}{l}\text { DATA. } \\
1504 / 01 / 02 .\end{array}$ \\
\hline (110) & Cullera & 1 fusta & Moros & Teulada & 1504/03/08. \\
\hline (111) & $\begin{array}{l}\text { Regent de la } \\
\text { Cancelleria }\end{array}$ & 7 fustes & Moros & Desconeguda & $1504 / 03 / 26$. \\
\hline (112) & Morvedre & 3 fustes & Moros-turcs & Mallorca & 1504/0s/13. \\
\hline (113) & Cullera & 2 fustes & Moros & Xàbia & 1504/06/07. \\
\hline (114) & Morvedre & 3 fustes & Moros & Cap d'Orpesa & $1504 / 06 / 28$ \\
\hline (115) & Morvedre & 4 fustes & Moros & Castell de Blanes & $1504 / 07 / 08$. \\
\hline (116) & Morvedre & 1 fusta & Moros & Cap d'Orpesa & $1504 / 07 / 31$. \\
\hline (117) & Peníscola & 6 fustes & Moros & Peníscola-Alcanar & $1504 / 08 / 01$. \\
\hline (118) & Morvedre & 6 fustes & Desconeguts & Tarragona & $1504 / 08 / 16$ \\
\hline (119) & Morvedre & 9 fustes & Moros & $\begin{array}{l}\text { Alcossèber- } \\
\text { Columbretes }\end{array}$ & $1504 / 08 / 21$. \\
\hline (120) & Morvedre & 6 fustes i 1 caire & Moros & Barcelona & $1504 / 08 / 22$. \\
\hline (121) & Eivissa & 2 fustes & Moros & Eivissa & $1504 / 10 / 04$ \\
\hline (122) & Cullera & 2 fustes & Turcs & Màlaga & $1505 / 02 / 12$. \\
\hline (123) & Cullera & 2 fustes & Moros & Guardamar & $1505 / 04 / 12$ \\
\hline (124) & Cullera & 6 fustes i 1 bergantí & Moros & Cullera & $1505 / 05 / 10$. \\
\hline (125) & Cullera & 4 fustes & Moros & Dénia & $1505 / 05 / 14$. \\
\hline (126) & Mallorca & 6 fustes & Turcs-Moros & Garraf & $1505 / 05 / 22$. \\
\hline (127) & Morvedre & 3 fustes & Moros & Benicarló & $1505 / 05 / 23$. \\
\hline (128) & Morvedre & 3 fustes & Moros & Grau de Castelló & $1505 / 05 / 25$. \\
\hline (129) & Cullera & 9 fustes & Moros & Oliva & $1505 / 05 / 29$. \\
\hline (130) & Morvedre & 1 fusta & Moros & Blanes & $1505 / 06 / 02$. \\
\hline
\end{tabular}

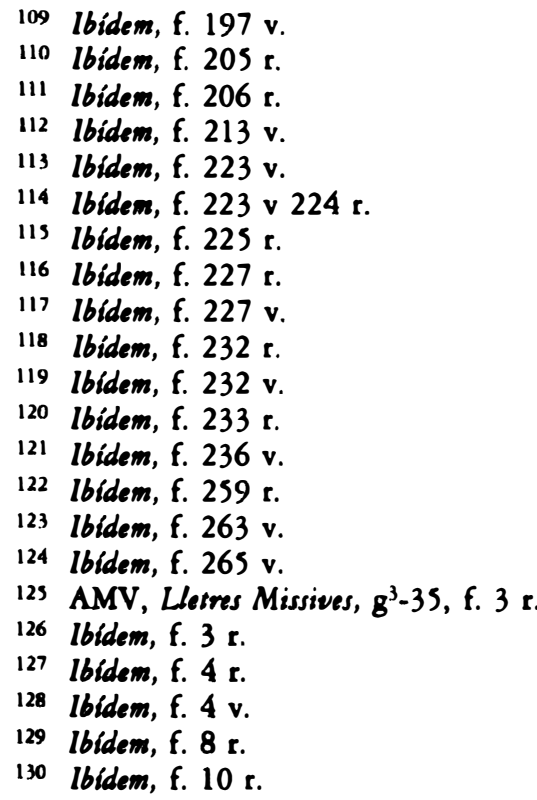




\begin{tabular}{|c|c|c|c|c|c|}
\hline $\begin{array}{l}\text { NOTA. } \\
(131)\end{array}$ & $\begin{array}{l}\text { PROCEDÉNCIA. } \\
\text { Alacant }\end{array}$ & $\begin{array}{l}\text { TIPUS DE VAIXELL. } \\
\text { Estol de grans } \\
\text { proporcions }\end{array}$ & $\begin{array}{l}\text { ENEMICS. } \\
\text { Moros-Turcs }\end{array}$ & $\begin{array}{l}\text { LOCALITZACIO } \\
\text { Barbaria }\end{array}$ & $\begin{array}{l}\text { DARA. } \\
1505 / 06 / 03 .\end{array}$ \\
\hline (132) & Cullera & 6 fustes & Moros & Santa Pola & $1505 / 06 / 28$ \\
\hline (133) & Cullera & 3 fustes & Moros & Calp & $1505 / 06 / 29$. \\
\hline (134) & Morvedre & 26 fustes & Moros-Turcs & Orà & $1505 / 07 / 09$. \\
\hline (135) & Morvedre & $\begin{array}{l}1 \text { galera, } 1 \text { bergantí i } \\
1 \text { fusta }\end{array}$ & Moros & Roses-Cadaqués & $1505 / 07 / 16$ \\
\hline (136) & Morvedre & 2 fustes & Moros & $\begin{array}{l}\text { Borriana-Grau } \\
\text { de Morvedre }\end{array}$ & $1505 / 07 / 16$. \\
\hline (137) & Cullera & 2 fustes & Moros & Cap de Cullera & 1505/07/22. \\
\hline (138) & Morvedre & 5 fustes & Moros & Estany de Nules & $1505 / 07 / 27$. \\
\hline (139) & Cullera & $\begin{array}{l}\text { Nombre indeterminat } \\
\text { de fustes }\end{array}$ & Moros & Teulada & $1505 / 07 / 27$. \\
\hline (140) & Morvedre & 2 fustes & Moros & Cap d'Orpesa & $1505 / 08 / 06$ \\
\hline (141) & Morvedre & $\begin{array}{l}\text { Nombre indeterminat } \\
\text { de fustes }\end{array}$ & Moros & Borriana & $1505 / 08 / 19$. \\
\hline (142) & Cullera & 2 fustes & Moros & Altea & $1505 / 08 / 20$ \\
\hline (143) & Cullera & 2 fustes & Moros & Dénia & $1505 / 08 / 21$. \\
\hline (144) & Morvedre & 1 galera & Desconeguts & Borriana & $1508 / 08 / 21$. \\
\hline (145) & Cullera & 1 balener & Moros & Illa de Benidorm & $1508 / 08 / 24$ \\
\hline (146) & Cullera & 1 fusta & Moros & Eivissa & 1506/04/02. \\
\hline (147) & Cullera & 5 fustes & Moros & Tagomago & 1506/05/13. \\
\hline (148) & Cullera & 7 fustes & Moros & Cap de Cullera & 1506/06/05. \\
\hline (149) & Morvedre & 5 fustes & Moros-Turcs & Cabrera & 1506/06/08. \\
\hline (150) & Cullera & 1 fusta & Desconeguts & Calp & $1506 / 06 / 25$. \\
\hline (151) & Cullera & 1 fusta & Moros & Santa Pola & 1506/08/03. \\
\hline$(152)$ & Cullera & 2 fustes & Moros & Penyes de l'Albir & $1506 / 08 / 17$ \\
\hline
\end{tabular}

\footnotetext{
131 lbidem, f. $10 \mathrm{r}$.

132 lbidem, f. 21 r.

133 Ibidem, f. 21 r.

134 lbidem, f. 23 r.

135 Ibidem, f. 27 r.

136 lbidem, f. 27 r.

137 Ibidem, f. 32 r.

138 lbidem, f. 36 r.

139 libidem, f. $36 \mathrm{v}$.

140 loidem, f. $37 \mathrm{v}$.

141 Ibidem, f. 42 r.

142 Ibidem, f. 42 v.

143 loidem, f. 43 r.

144 lobidem, f. 43 r.

149 Ibidem, f. 44 r.

146 Ibidem, f. $120 \mathrm{v}$.

147 Ibidem, f. $135 \mathrm{v}$.

148 Ibidem, f. $140 \mathrm{v}$.

149 Ibidem, f. 142 v.

$1 s 0$ Ibidem, f. 149 r.

151 Ibidem, f. 170 v.

132 Ibidem, f. 176 r.
} 


\begin{tabular}{|c|c|c|c|c|c|}
\hline $\begin{array}{l}\text { NOTA. } \\
(153)\end{array}$ & $\begin{array}{l}\text { PROCEDÈNCIA. } \\
\text { Morvedre }\end{array}$ & $\begin{array}{l}\text { TIPUS DE VAIXELL. } \\
2 \text { fustes }\end{array}$ & $\begin{array}{l}\text { ENEMICS. } \\
\text { Desconeguts }\end{array}$ & $\begin{array}{l}\text { LOCALITZACIÓ. } \\
\text { Tarragona }\end{array}$ & $\begin{array}{l}\text { DATA. } \\
1506 / 10 / 08\end{array}$ \\
\hline (154) & Cullera & 1 fusta & Moros & Dénia & $1506 / 10 / 15$ \\
\hline (155) & Cullera & 4 fustes & Moros & Calp & $1507 / 01 / 25$ \\
\hline (156) & Morvedre & 2 fustes & Moros & Benicarló & $1507 / 04 / 12$ \\
\hline (157) & Morvedre & 10 fustes & Moros & Cabanes & $1507 / 05 / 22$ \\
\hline (158) & Morvedre & 6 fustes & Desconeugts & Estany de Blanes & $1507 / 07 / 08$ \\
\hline (159) & Cullera & 4 fustes & Moros & Xabia & $1507 / 07 / 08$ \\
\hline (160) & Cullera & 1 fusta & Desconeguts & Gola de Cullera & $1507 / 08 / 1$ \\
\hline (161) & Cullera & 1 fusta & Desconeguts & Cap de Cullera & $1507 / 08 / 21$ \\
\hline (162) & Cullera & 1 fusta & Moros & Dénia-Gandia & $1508 / 01 / 25$ \\
\hline (163) & Cullera & 1 fusta & Moros & Penyal d'Ifac & $1508 / 01 / 26$ \\
\hline (164) & Cullera & 1 fusta & Moros & Cap de Cullera & $1508 / 03 / 18$ \\
\hline (165) & Vaixells sevillans & $\begin{array}{l}\text { Nombre } \mathrm{i} \text { tipus } \\
\text { indeterminat }\end{array}$ & Moros & Nord d'Àfrica & $1508 / 03 / 30$ \\
\hline (166) & Morvedre & 1 fusta & Turcs & Salines de Borrian & a $1508 / 11 / 13$ \\
\hline (167) & Cullera & 1 fusta & Moros & Calp & $1509 / 04 / 18$ \\
\hline (168) & Morvedre & 1 fusta & Moros & Mataró & $1509 / 06 / 30$ \\
\hline (169) & Mallorca & 3 fustes & Moros & Cabrera & $1511 / 05 / 23$ \\
\hline (170) & Morvedre & 2 fustes de gàbia & Desconeguts & $\begin{array}{l}\text { Cap de Canet } \\
\text { (Colliure) }\end{array}$ & $1511 / 08 / 11$ \\
\hline (171) & Eivissa & 2 galions & Desconeguts & Mallorca & $1513 / 03 / 08$ \\
\hline (172) & Morvedre & 2 fustes & Francesos & Cadaqués & $1513 / 04 / 06$ \\
\hline (173) & Eivissa & $\begin{array}{l}\text { Nombre i tipus } \\
\text { indeterminat }\end{array}$ & Desconeguts & Desconeguda & $1513 / 06 / 0$ \\
\hline 14) & Morvedre & 20 fustes & Turcs & Menorca & $1513 / 06 / 0$ \\
\hline 175) & Cullera & 6 fustes & Moros & Cap de Martí & $1513 / 06 / 0$ \\
\hline
\end{tabular}

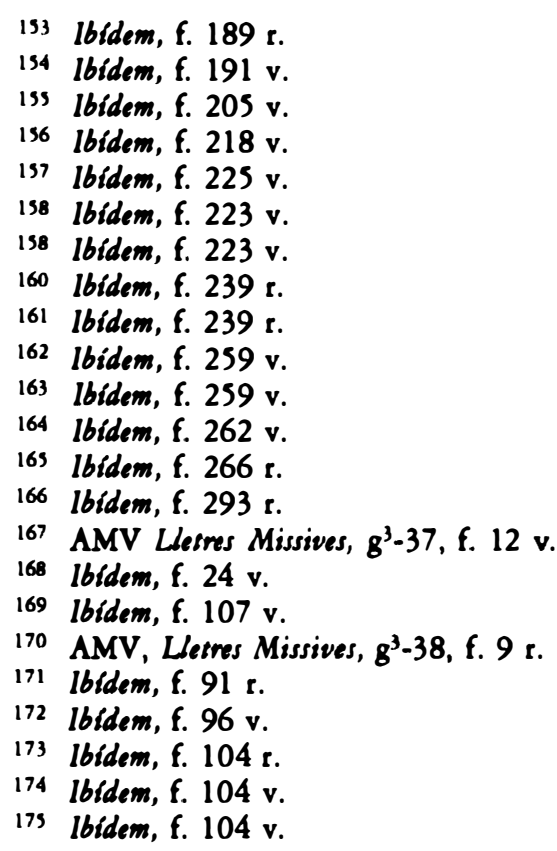




\begin{tabular}{|c|c|c|c|c|c|}
\hline $\begin{array}{l}\text { NOTA. } \\
(176)\end{array}$ & $\begin{array}{l}\text { PROCEDĖNCIA. } \\
\text { Cullera }\end{array}$ & $\begin{array}{l}\text { TIPUS DE VAIXELL. } \\
6 \text { fustes }\end{array}$ & $\begin{array}{l}\text { ENEMICS. } \\
\text { Desconeguts }\end{array}$ & $\begin{array}{l}\text { LOCALITZACIÓ. } \\
\text { Dénia }\end{array}$ & $\begin{array}{l}\text { DATA. } \\
1513 / 06 / 13\end{array}$ \\
\hline (177) & Morvedre & 6 fustes & Moros & Palamós & $1513 / 07 / 07$. \\
\hline (178) & Eivissa & 3 fustes & Moros & Andratx & 1514/0s/08. \\
\hline (179) & Cullera & 8 fustes & Desconeguts & La Granadella & 1514/05/11. \\
\hline (180) & Morvedre & 3 fustes & Moros & Tortosa & $1514 / 05 / 15$. \\
\hline (181) & Morvedre & 2 fustes & Moros & Illes Medes & $1514 / 05 / 31$. \\
\hline (182) & Cullera & 1 fusta & Moros & Illa de Benidorm & 1514/06/05. \\
\hline (183) & Cullera & 1 fusta & Moros & Altea & $1514 / 06 / 07$ \\
\hline (184) & Morvedre & 3 fustes & Moros & Colliure & $1514 / 06 / 15$ \\
\hline (185) & Morvedre & 4 fustes & Turcs & Montjuïc & 1514/07/05. \\
\hline (186) & Morvedre & 2 fustes & Moros & Cap de Tortosa & $1514 / 07 / 18$ \\
\hline (187) & Cullera & 2 galeres i 3 fustes & Turcs & Santa Pola & $1514 / 07 / 28$ \\
\hline (188) & Alacant & 7 fustes & Moros & Alacant & $1514 / 08 / 01$. \\
\hline (189) & Morvedre & 3 fustes & Desconeguts & Barcelona & $1515 / 04 / 06$. \\
\hline (190) & Cullera & 40 fustes & Moros & Tunis & $1515 / 04 / 19$ \\
\hline (191) & Morvedre & 9 fustes & Desconeguts & Moraira & $1515 / 05 / 04$ \\
\hline (192) & Morvedre & 1 fusta & Moros & Orpesa & $1515 / 05 / 26$ \\
\hline (193) & Morvedre & 5 fustes & Desconeguts & Cap d'Orpesa & $1515 / 05 / 28$ \\
\hline (194) & Cullera & 3 fustes & Turcs & Cap de l'Aljub & $1515 / 06 / 04$ \\
\hline (195) & Cullera & 3 fustes & Desconeguts & Penyes de l'Albir & $1515 / 06 / 11$ \\
\hline (196) & Eivissa & $\begin{array}{l}\text { Nombre i tipus } \\
\text { indeterminat }\end{array}$ & Desconeguts & Desconeguda & $1515 / 07 / 11$ \\
\hline (197) & Morvedre & Estol pirata & $\begin{array}{l}\text { Pedro } \\
\text { Navarro }\end{array}$ & Agde & $1515 / 07 / 2$ \\
\hline (198) & Morvedre & 1 fusta & Desconeguts & Cap de Tortosa & $1515 / 09 / 05$ \\
\hline (199) & Culera & 1 fusta & Francesos & Moraira & $1516 / 01 / 25$ \\
\hline
\end{tabular}

177 Ibidem, f. 115 r.

178 Ibidem, f. $151 \mathrm{r}$.

179 lbidem, f. $151 \mathrm{rv}$.

180 lbidem, f. 151 v.

181 lbidom, f. 152 r.

$182 A M V$, Lletres Missives, $\mathrm{g}^{3}-39$, f. 1 r.

183 lbidem, f. 1 r.

184 lbidem, f. $11 \mathrm{v}$.

18s lbidem, f. 7 r.

186 lbidem, f. 10 r.

187 lbidem, f. 15 r.

188 Ibidem, f. $15 \mathrm{v}$.

189 lbidem, f. 85 r.

190 lbidem, f. 85 r.

191 Ibidem, f. 89 v.

192 Ibidem, f. 93 v.

193 Ibidem, f. 104 r.

194 Ibidem, f. $104 \mathrm{v}$.

195 Ibidem, f. 105 r.

196 Ibidem, f. 108 r.

197 Ibidem, f. 112 r.

198 lbidem, f. 125 v 126 r.

199 Ibidem, f. 150 r. 


\begin{tabular}{|c|c|c|c|c|c|}
\hline $\begin{array}{l}\text { NOTA. } \\
(200)\end{array}$ & $\begin{array}{l}\text { PROCEDE்NCIA. } \\
\text { Morvedre }\end{array}$ & $\begin{array}{l}\text { TIPUS DE VAIXELL. } \\
2 \text { fustes }\end{array}$ & $\begin{array}{l}\text { ENEMICS. } \\
\text { Provençals }\end{array}$ & $\begin{array}{l}\text { LOCALITZACIÓ. } \\
\text { Grau de Marsella }\end{array}$ & $\begin{array}{l}\text { DATA. } \\
1516 / 02 / 07 .\end{array}$ \\
\hline$(201)$ & Morvedre & 1 navili i 1 caravel la & Desconeguts & Barcelona-Salou & $1516 / 02 / 16$ \\
\hline (202) & Cullera & $\begin{array}{l}9 \text { fustes i 10-11 fustes } \\
\text { més }\end{array}$ & $\begin{array}{l}\text { Desconeguts- } \\
\text { moros }\end{array}$ & $\begin{array}{l}\text { Benidorm-Grana- } \\
\text { della-Xàbia }\end{array}$ & $1516 / 05 / 11$. \\
\hline (203) & Cullera & 20 fustes & Moros & $\begin{array}{l}\text { Illa Grossa (Cap } \\
\text { de Pals) }\end{array}$ & $1516 / 05 / 12$ \\
\hline (204) & Cullera & 11 fustes & Desconeguts & Cap de Martí & $1516 / 05 / 15$ \\
\hline (205) & Eivissa & 9 fustes & Moros & Formentera & $1516 / 05 / 18$ \\
\hline (206) & Morvedre & $11-13$ fustes & Desconeguts & Peníscola & 1516/0s/21. \\
\hline (207) & Morvedre & 2 fustes & Desconeguts & Torreblanca & 1516/05/25. \\
\hline (208) & Cullera & 13 fustes & Moros & La Granadella & 1516/07/21. \\
\hline (209) & Mallorca & 2 galeres i 2 fustes & Moros & Illa Dragonera & 1516/07/23. \\
\hline (210) & Morvedre & 4 fustes & Desconeguts & Grau de Castello & $1516 / 07 / 23$. \\
\hline (211) & Morvedre & $\begin{array}{l}\text { Nombre i tipus } \\
\text { indeterminat }\end{array}$ & Desconeguts & Peníscola & Desconeguda. \\
\hline (212) & Cullera & 7 fustes & Moros & Illa Grossa & $1517 / 04 / 30$. \\
\hline (213) & Cullera & 6 fustes & Desconeguts & Cala de Lloret & 1517/0s/0s. \\
\hline (214) & Morvedre & 3 fustes & Turcs & Peníscola & $1517 / 05 / 18$ \\
\hline (215) & Morvedre & 5 fustes & Turcs & Barcelona & $1517 / 06 / 24$. \\
\hline (216) & Morvedre & 3 fustes & Moros-Turcs & Mallorca & 1517/07/06. \\
\hline (217) & Cullera & 1 fusta & Moros & Cap de Martí & 1517/07/10. \\
\hline (218) & Cullera & 5 fustes & Desconeguts & $\begin{array}{l}\text { Cap de Moraira- } \\
\text { Penyal d'Ifac }\end{array}$ & 1518/06/15. \\
\hline (219) & Mallorca & 7 fustes & Moros & $\begin{array}{l}\text { Cala Sant Vicent } \\
\text { (Pollença-Alcúdia) }\end{array}$ & $1518 / 06 / 18$ \\
\hline (220) & Cullera & $10-12$ fustes & Moros & Cartagena & $1518 / 11 / 20$. \\
\hline
\end{tabular}

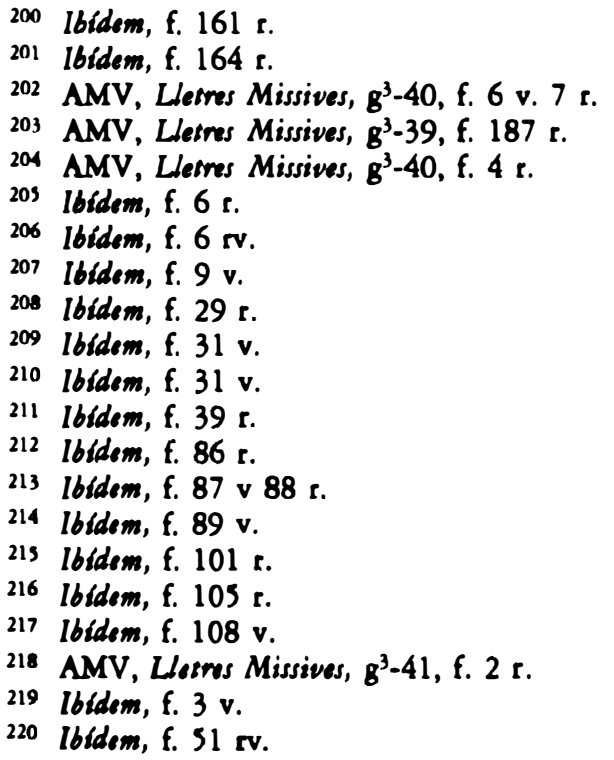




\begin{tabular}{|c|c|c|c|c|c|}
\hline NOTA. & PROCEDĖNCIA. & TIPUS DE VAIXELL. & ENEMICS. & LOCALITZACIÓ. & $\begin{array}{l}\text { DATA. } \\
1510 / 05 / 27\end{array}$ \\
\hline $\begin{array}{l}(221) \\
(222)\end{array}$ & $\begin{array}{l}\text { Cullera } \\
\text { Cullera }\end{array}$ & $\begin{array}{l}1 \text { fusta } \\
4 \text { fustes }\end{array}$ & Moros & Cap de Martí & $\begin{array}{l}1519 / 05 / 27 . \\
1519 / 05 / 28\end{array}$ \\
\hline (223) & Cullera & 11 fustes & Moros & Moraira & $1519 / 06 / 04$. \\
\hline (224) & Cullera & 13 fustes & Moros & Xàbia & $1519 / 06 / 07$. \\
\hline (225) & Cullera & 4 fustes i 1 galera & Turcs & Eivissa & 1519/06/28. \\
\hline (226) & Cullera & 1 fusta & Moros & $\begin{array}{l}\text { Cap de Sant } \\
\text { Antoni }\end{array}$ & 1519/07/07. \\
\hline (227) & Cullera & 1 fusta & Desconeguts & Penyes de l'Albir & 1519/09/09. \\
\hline (228) & Cullera & 1 fusta & Moros & Dénia & $1520 / 03 / 22$. \\
\hline (229) & Cullera & 1 fusta & Moros & Benidorm & $1520 / 03 / 27$. \\
\hline (230) & Morvedre & 1 fusta & Moros & Peníscola & $1520 / 04 / 03$. \\
\hline (231) & Cullera & 4 fustes & Moros & Cap de Martí & $1520 / 05 / 18$. \\
\hline (232) & Morvedre & 4 fustes & Moros & Mallorca & $1520 / 05 / 30$. \\
\hline (233) & Alacant & 20 fustes & Moros & Salines d'Alacant & $1520 / 06 / 11$. \\
\hline (234) & Cullera & $\begin{array}{l}\text { Nombre i tipus } \\
\text { indeterminat }\end{array}$ & Moros & Benissa & $1520 / 06 / 14$. \\
\hline (235) & Eivissa & $\begin{array}{l}\text { Nombre i tipus } \\
\text { indeterminat }\end{array}$ & Desconeguts & Desconeguda & $1520 / 08 / 16$. \\
\hline (236) & Cullera & 1 fusta & Desconeguts & Altea & $1520 / 08 / 21$. \\
\hline (237) & Morvedre & 1 fusta & Moros & Orpesa & 1520/08/22. \\
\hline (238) & Cullera & 1 fusta & Moros & Calp & $1520 / 08 / 22$. \\
\hline (239) & Cullera & $\begin{array}{l}\text { Nombre } \mathrm{i} \text { tipus } \\
\text { indeterminat }\end{array}$ & Moros & Vila Joiosa & $1520 / 08 / 23$. \\
\hline (240) & Cullera & 2 fusta & Moros & Vila Joiosa & $1520 / 08 / 26$. \\
\hline (241) & Morvedre & 1 fusta & Moros & Borriana & $1520 / 09 / 03$. \\
\hline (242) & Cullera & 2 fusta & Moros & Cap de Martí & $1520 / 09 / 07$. \\
\hline
\end{tabular}

\footnotetext{
221 Ibidem, f. 89 r.

222 Ibidem, f. 89 v.

223 lbidem, f. 95 r.

224 lbidem, f. 96 v.

225 Ibidem, f. 105 v.

226 lbidem, f. 108 r.

227 Ibidem, f. 121 r.

228 Ibidem, f. 151 r.

229 Ibidem, f. 151 v.

230 Ibidem, f. 152 r.

231 lbidem, f. 156 r.

232 Ibidem, f. 159 r.

233 lbidem, f. $161 \mathrm{v}$.

234 Ibidem, f. 168 r.

23s Ibidem, f. 187 r.

236 Ibidem, f. 188 v.

237 lbidem, f. 190 r.

238 Ibidem, f. 179 v.

239 Ibidem, f. 180 r.

240 Ibidem, f. $190 \mathrm{v}$.

241 lbidem, f. 194 r.

242 lbidem, f. 195 r.
} 
En aquest marc, els francesos empraren de manera indistinta naus, bergantins, galeres, galeons o caravel ·es, aquest dos últims tipus amb un prometedor futur per davant, i de tracció a vela. En definitiva, s'ha de constatar que una important porció dels avisamentes fan referència constantment a vaixells d'aquest tipus, per la qual cosa es pot deduir que es tractava d'enemics cristians. No podem afirmar el mateix d'altres casos que ens parlen de fustes de dimensions més menudes, i que nosaltres hem considerat musulmans perqùe s'adapten millor a les possibilitats i necessitats barbaresques.

Per últim, cal fer una breu reflexió sobre els objectius dels pirates i corsaris cristians. Amb aquesta finalitat, és interessant que recordem que els pirates islàmics se sentien més atrets pels assalts i per les incursions a les petites localitats costenques, embarcacions de pescadors o preses facils de les quals es poguessen obtenir captius i, en menor mesura, valuosos béns per a vendre'ls en llurs ports base. Pel que toca a la pirateria genovesa i francesa, aquestes se sentiran més inclinades a actuar de manera molt diferent, puix que incidiran, fonamentalment, sobre els grans ancoratges catalano-aragonesos, Barcelona, València, etc., amb uns objectius més ensolcats cap a la destrucció de navilis que vers l'obtenció de botins. Aquesta actitud no era promoguda per motius aleatoris sinó que més bé responia a fonaments de pes i a raons minuciosament meditades. En aquest sentit, la guerra catalano-aragonesa que es perllongarà durant dècades, per a escatir l'hegemonia marítima sobre el Mediterrani Occidental i per a controlar els comerços mercants, generarà una autèntica guerra de desgast, en la qual la filosofia dels atacs a ports i altres colps d'efecte d'aquest caire quadraven perfectament. Posteriorment, les esquadres franceses imitaran aquestes tàctiques.

\section{BALANÇ FINAL}

El període que va entre els anys 1480 i 1520 pot considerar-se com l'època més espectacular en l'Era dels Descobriments, com un moment clau per a la història marítima, tant a nivell dels països que protagonitzaren directament aquella vasta empresa com per als països que hom pot considerar-ne protagonistes passius. El País Valencià i totes les terres de la façana mediterrània peninsular, en el seu conjunt, es van veure sotmesos a la pressió corsària de moltes diverses maneres. Així, doncs, dintre de la panoràmica general de l'estudi de la pirateria a València, l'anàlisi dels albiraments costaners és una de les fonts que més ens pot ajudar a aclarir les línies mestres d'aquest important fenòmen, en una època concreta. Per tant, les notícies d'alerta litoral es constitueixen en una documentació essencial $i$ imprescindible a l'hora d'investigar el problema susdit. Ara bé, açò només és possible si partim de la base de comptar amb un arxiu que ens oferesca tota una sèrie de dades cronològiques de forma suficientment continuada i completa com per a permetre'ns analitzar i esbossar un seguiment temporal de llarga durada. En aquest punt, l'Arxiu Municipal de València compta amb uns fons, des del nostre punt de mira, extraordinaris, que ens serveixen perfectament per a escometre aquesta tasca d'anàlisi amb certes garanties d'èxit. En conseqüència, gràcies als avisaments costanencs som capaços, a nivel estadístic, de tenir una mínima idea del nombre total dels albiraments de 
vaixells enemics de la Confederació, durant aquets període tan decisiu. A més a més, coneixerem el tipus d'embarcacions emprades, de quin divers gènere de pirates es tractava, on foren descoberts i per mitjà de quin procediment arribaven les notícies a la capital valentina, sense oblidar, per supost, la data aproximada de la seua localització. Totes aquestes dades són, en certa mesura, suficients per a tenir una visió global del món del cors i endemés són fonamentals per a poder abordar la qüestió amb veritable profunditat. És per tot això que hem considerat digne d'estudi l'anàlisi dels avisos costaners, ja que representen una documentació quelcom més indispensable per a la investigació de la pirateria baixmedieval a la Mediterrània Occidental.

\author{
ANDRÉS DÍAZ BORRÁS \\ Departament de Paleografia \\ Universitat de València
}

